\title{
European Calcified
}

Tissue Society

\section{Membership}

The European Calcified Tissue Society is the major organisation in Europe for researchers and clinicians working in the field of calcified tissues and related fields. For over $\mathbf{4 0}$ years the Society has acted as a forum for broad-ranging high quality research through its annual meetings and workshops. The Society's strength lies in its members and we invite you to join them. Benefits of membership include free or reduced subscription to the journals Calcified Tissue International and Osteoporosis International. Membership is open to anyone working in the field at whatever stage in their career and from anywhere in the world.

\section{Benefits of joining the ECTS:}

- 12 months' on-line access to the Society's official journal, Calcified Tissue International (CTI), with the option to take out a subscription to the paper copy at a members'-only discount rate

- Reduced subscription rate for Osteoporosis International (Ol)

- Reduced registration fee for workshops, ECTS meetings and courses

- Travel grants for student/trainee members to attend ECTS meetings

- Awards for best poster and oral presentation from student/trainee members

- An opportunity for members to apply for ECTS Exchange Scholarship Grants to support visits of up to 3 months to other laboratories

- The option of being actively involved with the running and organisation of the ECTS

- A chance to contribute to the development of the field of calcified tissues in Europe and beyond

\section{What is the cost?}

Full membership

(on-line access to $C T I$ included):

Student membership

PhD students or undergraduates:

(NB: Head of Department to

sign application form)

(for on-line access to CTI. students

have to sign up for full membership)

Paper copy of CTI: additional

Members' subscription rate to OI

On-line access:

Paper copy (includes on-line access):

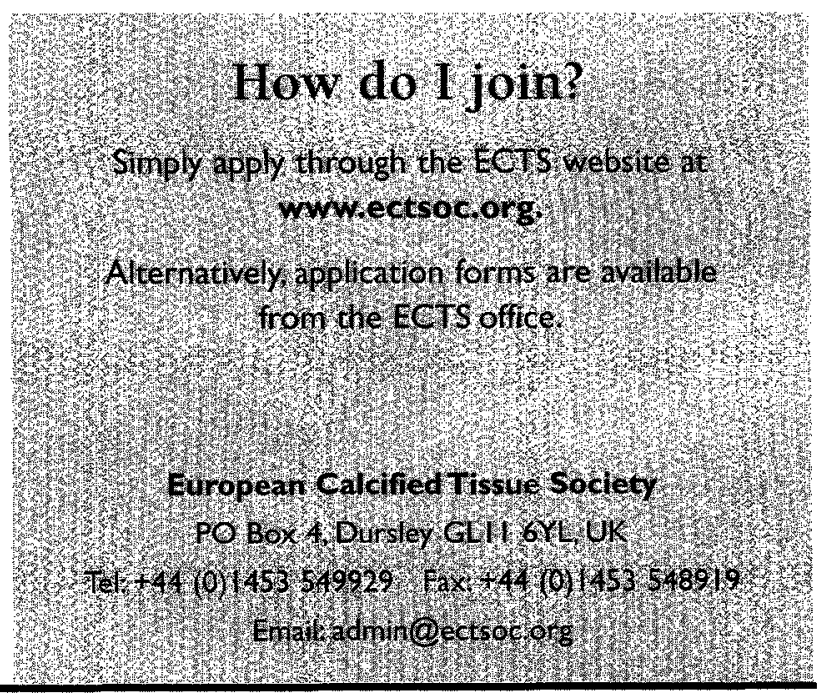

